\title{
Optimization of Fenton-based treatment of petroleum refinery wastewater with scrap iron using response surface methodology
}

\author{
Ali Saber • Hasti Hasheminejad • Amir Taebi • \\ Ghasem Ghaffari
}

Received: 18 July 2013/Accepted: 25 November 2013/Published online: 13 December 2013

(c) The Author(s) 2013. This article is published with open access at Springerlink.com

\begin{abstract}
The ever-increasing number and production capacity of petroleum refineries in recent years have intensified the need for developing an effective and practical method for treating their wastewaters. In this study, the application of Fenton process with scrap iron powder was investigated for the treatment of a bio-refractory petroleum refinery effluent. Response surface methodology was employed with a cubic IV optimal design to optimize the process using chemical oxygen demand (COD) removal as the target response. $\mathrm{H}_{2} \mathrm{O}_{2} / \mathrm{COD}$, and $\mathrm{H}_{2} \mathrm{O}_{2} / \mathrm{Fe}$ mass ratios as well as $\mathrm{pH}$ were considered as the relevant parameters. A COD removal of more than $83 \%$ was achieved under optimal conditions $\left(\mathrm{H}_{2} \mathrm{O}_{2} / \mathrm{COD} 10.03\right.$, $\mathrm{H}_{2} \mathrm{O}_{2} / \mathrm{Fe} 2.66$ and $\mathrm{pH} 3.0$ ) within 90 min. Kinetics studies were conducted to investigate the effect of reaction time on COD removal. In addition, the role of post-coagulation on COD removal under optimal conditions was investigated and it was found that $37 \%$ of COD removal occurred due to coagulation, indicating its high potential in the Fenton process.
\end{abstract}

Keywords Petroleum refinery wastewater · Fenton-based treatment - Scrap iron - Response surface methodology $(\mathrm{RSM}) \cdot$ Post-coagulation

\footnotetext{
A. Saber $\cdot$ H. Hasheminejad $(\varangle) \cdot$ A. Taebi Environmental Engineering Division, Department of Civil Engineering, Isfahan University of Technology, 84154 Isfahan, Iran

e-mail: hhasheminejad@cc.iut.ac.ir

G. Ghaffari

Isfahan Oil Refining Company, Isfahan, Iran
}

\section{Introduction}

Refining of crude oil is associated with the generation of large amounts of wastewater (0.4-0.6 times the volume of the oil processed) (Coelho et al. 2006). The demand for reduced water consumption in the industry warrants the development of water treatment and water recycle technologies for the oil industry (Saien and Nejati 2007). Petroleum refinery effluents contain large quantities of such toxic and recalcitrant aromatic compounds as Benzene, Toluene, Ethyl benzene, and Xylene which are recognized as the most hazardous compounds released into the environment (Aranda et al. 2010; Tiburtius et al. 2005). The conventional methods used for treating refinery wastewaters include mechanical and physicochemical processes such as oilwater separation, coagulation, and dissolved air flotation with further biological treatment (Stepnowski et al. 2002; Diya'uddeen et al. 2011). However, biological processes are not efficient when the wastewater contains highly toxic and bio-refractory compounds (Saien and Nejati 2007).

Advanced oxidation processes characterized by the generation of hydroxyl radicals $(\mathrm{OH})$ can be used to destroy a wide range of toxic and bio-refractory compounds. Among these, the Fenton process which utilizes a mixture of hydrogen peroxide and ferrous ions to generate hydroxyl radicals has proved to be an effective and economical method (Eq. 1) (Stepnowski et al. 2002; Chu et al. 2012).

$\mathrm{Fe}^{2+}+\mathrm{H}_{2} \mathrm{O}_{2} \rightarrow \mathrm{Fe}^{3+}+\mathrm{OH}^{\cdot}+\mathrm{OH}^{-}$

A number of researchers have investigated the Fenton process using alternative iron sources to find that iron powder could be replaced by iron salts as the catalyst in the Fenton reaction. In this case, $\mathrm{Fe}^{2+}$ is generated due to the corrosion of iron in the presence of $\mathrm{H}_{2} \mathrm{O}_{2}$ under acidic conditions which would then react with hydrogen peroxide 
(Barbusiński and Majewski 2003; Su et al. 2011; Chang et al. 2009). Ferric ions in the solution may react with hydrogen peroxide and yield ferrous ions and hydroperoxyl radicals. This reaction is referred as Fenton-like reaction (Hasan et al. 2012). In addition, ferric ions existing in the solution can improve the treatment process by coagulation of organic compounds. The proposed reaction mechanism is shown in Eqs. (2, 3, 4, 5) (Kallel et al. 2009; Benatti et al. 2006; Hasan et al. 2012).

$$
\begin{aligned}
& \mathrm{Fe}^{0}+2 \mathrm{H}^{+} \rightarrow \mathrm{Fe}^{2+}+\mathrm{H}_{2} \\
& 2 \mathrm{Fe}^{3+}+\mathrm{Fe}^{0} \rightarrow 3 \mathrm{Fe}^{2+} \\
& \mathrm{Fe}^{3+}+\mathrm{H}_{2} \mathrm{O}_{2} \leftrightarrow \mathrm{Fe} \ldots \mathrm{OOH}^{2+} \\
& \mathrm{Fe} \ldots \mathrm{OOH}^{2+}+\mathrm{H}^{+} \leftrightarrow \mathrm{Fe}^{2+}+\mathrm{H}_{2} \mathrm{O}+\mathrm{H}^{+}
\end{aligned}
$$

Fenton-like reaction with the constant rate of $0.01-0.02 \mathrm{M}^{-1} \mathrm{~s}^{-1}$ is much slower than Fenton reaction with the constant rate of $76 \mathrm{M}^{-1} \mathrm{~s}^{-1}$, moreover $\mathrm{HO}_{2}$ is less reactive than $\mathrm{OH}$; thus, Fenton is the dominant reaction in production of the radicals (Anotai et al. 2006; Sun et al. 2007; Ramirez et al. 2009). In general, regeneration of ferrous iron from the Fenton-like reaction is the rate limiting step in the iron cycle. As a result, after consumption of ferrous ions by the Fenton reaction, the generation of radicals will considerably slow down (Kavitha and Palanivelu 2004; Anotai et al. 2006).

Industrial wastewater treatment plants deal with problems related to the variability of wastewater characteristics. Therefore, the concentrations of the reagents used should be adjusted to meet optimal treatment conditions (Bianco et al. 2011). Response surface methodology (RSM) is a powerful method to determine optimal operating conditions for processes with a wide variability and different interactions (Ahmadi et al. 2005).

In this study, the Fenton treatment (combination of advanced oxidation and post-coagulation processes) was used with scrap iron powder for the treatment of a biorefractory petroleum refinery effluent. Response surface methodology with a cubic IV optimal design was used to evaluate and optimize the process. The effects of the parameters involved in the Fenton process including the ratios of hydrogen peroxide to COD and hydrogen peroxide to $\mathrm{Fe}, \mathrm{pH}$, and reaction time were also investigated.

\section{Materials and methods}

\section{Materials}

The effluent from the $\mathrm{API}^{1}$ process was obtained from a plant located in Isfahan Oil Refining Co. in Iran; the

\footnotetext{
1 - American Petroleum Institute

Table 1 Characteristics of raw wastewater

\begin{tabular}{lc}
\hline Item & Value \\
\hline COD (mg/L) & 450 \\
BOD (mg/L) & 174 \\
TOC (mg/L) & 119 \\
Oil and grease (mg/L) & 870 \\
TSS (mg/L) & 150 \\
pH & 6.7 \\
\hline
\end{tabular}

process is commonly employed for treating wastewaters from lubrication oil manufacturing plants. Due to the high bio-refractory content of the wastewater, the effluent is transferred into an evaporation pond. The characteristics of the wastewater used in this study are presented in Table 1.

All chemicals $\left(\mathrm{NaOH}, \mathrm{HCl}, \mathrm{H}_{2} \mathrm{SO}_{4}, \mathrm{H}_{2} \mathrm{O}_{2} 30 \%\right)$ were purchased from Merck (analytical grade). Scrap iron shavings were obtained from a metal tuner. Iron particles were prepared by sieving them and particles ranging between 106 and $300 \mu \mathrm{m}$ (No. 140-50) in diameters were selected for the experiments. The particles were washed in $\mathrm{H}_{2} \mathrm{SO}_{4}(0.6 \mathrm{M})$ for $10 \mathrm{~min}$, and in distilled water before they were washed in $\mathrm{NaOH}(1 \mathrm{M})$ for $10 \mathrm{~min}$ to remove lipids on the surface of the particles ( $\mathrm{Mu}$ et al. 2004). Finally, they were washed in distilled water again to remove residual $\mathrm{NaOH}$.

\section{Experimental procedure}

As shown in Fig. 1, the experiments were carried out with samples of $400 \mathrm{~mL}$ of wastewater in $1 \mathrm{~L}$ containers. $\mathrm{NaOH}$ (1 M) and $\mathrm{HCl}(2 \mathrm{M})$ were used for $\mathrm{pH}$ adjustment. The Fenton process was conducted at room temperature $\left(25^{\circ} \mathrm{C}\right)$ in the batch mode using predetermined concentrations of reagents. A six-blade jar test apparatus was used for agitation $(200 \mathrm{rpm})$ throughout the process. Containers with square cross sections $(10 \mathrm{~cm} \times 10 \mathrm{~cm})$ were used to provide complete agitation.

At the end of the reaction time (90 min), oxidation was terminated by adjusting $\mathrm{pH}$ to 8.5 . This $\mathrm{pH}$ value also falls within the optimum range for the coagulation process reported by many researchers (Altaher et al. 2011; Tchobanoglous et al. 2003; Yoon et al. 2002). Hydrogen peroxide breaks down into oxygen and water at $\mathrm{pH}$ values above 7.0 (Kallel et al. 2009). It is important to note that each $\mathrm{mg} / \mathrm{L}$ of residual $\mathrm{H}_{2} \mathrm{O}_{2}$ in solution is equivalent to $0.27 \mathrm{mg} / \mathrm{L}$ of COD (Ahmadi et al. 2005). Residual $\mathrm{H}_{2} \mathrm{O}_{2}$ must, therefore, be allowed to decompose to avoid interference with COD measurement (Anotai et al. 2010; Coelho et al. 2006). The sludge in samples with a high initial $\mathrm{H}_{2} \mathrm{O}_{2}$ concentration cannot settle due to the presence 


\section{Jar test apparatus}

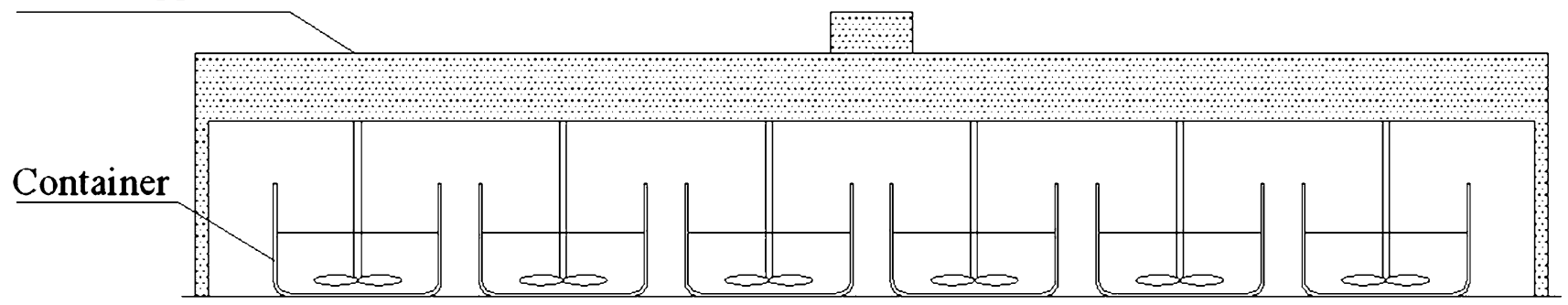

Fig. 1 Schematic diagram of the Fenton reactor

of bubbles produced by the decomposition of residual hydrogen peroxide. Hence, $50 \mathrm{~mL}$ of each sample was transferred into capped containers and kept at $75{ }^{\circ} \mathrm{C}$ for $5 \mathrm{~h}$. After simultaneous precipitation and coagulation of $\mathrm{Fe}^{3+}$ in the form of $\mathrm{Fe}(\mathrm{OH})_{3}$, the supernatant was decanted and subjected to analyses.

Analyses

COD was measured according to the colorimetric method for COD in the range of $0-1,500 \mathrm{mg} / \mathrm{L}$ using a $\mathrm{HACH} \mathrm{DR} /$ 2010 spectrophotometer. COD removal efficiency was defined as in the following Equation:

COD removal $(\%)=\frac{\mathrm{COD}_{\mathrm{i}}-\mathrm{COD}_{\mathrm{f}}}{\mathrm{COD}_{\mathrm{i}}}$

where $\mathrm{COD}_{\mathrm{i}}$ and $\mathrm{COD}_{\mathrm{f}}$ designate the measured COD values before and after the Fenton process, respectively.

The $\mathrm{pH}$ of wastewater was measured using a 3045 Ion Analyzer $\mathrm{pH}$ meter. All other analytical tests were performed according to the standard methods for examination of water and wastewater (Eaton et al. 2005).

Experimental design and optimization

Experiments were carried out in a cubic IV optimal design using the RSM to investigate the effects of the parameters involved. The IV optimal design seeks to minimize the integral of prediction variance across the entire design space. Moreover, it is built algorithmically to provide a lower prediction variance throughout a region of interest (Design Expert software, version 8, user's Guide 2010).

The mass ratios of $\mathrm{H}_{2} \mathrm{O}_{2} / \mathrm{COD}$ and $\mathrm{H}_{2} \mathrm{O}_{2} / \mathrm{Fe}$ as well as $\mathrm{pH}$ were considered as independent variables and COD removal efficiency was considered as the response. Variable levels were determined based on both stoichiometric studies and literature reports to ensure that the design points fell within the design space. The calculation of minimum $\mathrm{H}_{2} \mathrm{O}_{2}$ dosage was based on the stoichiometric ratio with respect to complete oxidation of $\mathrm{COD}$ as
Table 2 Experimental factors and levels

\begin{tabular}{lllllll}
\hline Factor & Level & & & & & \\
\hline $\mathrm{H}_{2} \mathrm{O}_{2} / \mathrm{COD}(\mathrm{g} / \mathrm{g})$ & 1.5 & 3.5 & 5.5 & 7.5 & 9.5 & 11.5 \\
$\mathrm{H}_{2} \mathrm{O}_{2} / \mathrm{Fe}(\mathrm{g} / \mathrm{g})$ & 0.35 & 0.88 & 1.41 & 1.94 & 2.47 & 3 \\
$\mathrm{pH}$ & 2.0 & 3.0 & 4.0 & 5.0 & - & - \\
\hline
\end{tabular}

presented in the following Equation (Badawy et al. 2006; Gernjak et al. 2003).

$$
\begin{aligned}
1 \mathrm{~g} \mathrm{COD} & =1 \mathrm{~g} \mathrm{O}_{2}=0.03125 \mathrm{~mol} \mathrm{O}_{2} \\
& =0.0625 \mathrm{~mol} \mathrm{H}_{2} \mathrm{O}_{2}=2.125 \mathrm{~g} \mathrm{H}_{2} \mathrm{O}_{2}
\end{aligned}
$$

The variables and design levels are presented in Table 2.

The experiment design, optimization, and the 3D response surface plot were accomplished using the DesignExpert software, version 8.0.7.1 (Stat-Ease, Inc., USA). The optimal conditions determined by the software were used for investigating the reaction time and kinetics in the next steps.

\section{Results and discussion}

In order to investigate the factors (mass ratios of $\mathrm{H}_{2} \mathrm{O}_{2}$ / $\mathrm{COD}, \mathrm{H}_{2} \mathrm{O}_{2} / \mathrm{Fe}$ and $\mathrm{pH}$ ) involved in the Fenton reaction, 30 sets of experiments with operating conditions according to the experimental design were performed. All the experiments were conducted during a reaction time of $90 \mathrm{~min}$. A mass-based computation was used for better evaluation of the treatment process. Table 3 presents the experimental results under each operating conditions based on the IV optimal design.

A cubic model was used for design of experiments due to the likelihood of a wavy response and high interactions among the parameters (Design Expert software, version 8, user's Guide 2010). Analysis of variance was performed to evaluate the interactions among the variables and for model calibration according to experimental results (Table 4).

All the statistically non-significant terms were eliminated from the model. The following equation with coded 
Table 3 Experimental results at each operating conditions based on IV optimal design

\begin{tabular}{|c|c|c|c|c|}
\hline Run & $\begin{array}{l}\text { A: } \mathrm{H}_{2} \mathrm{O}_{2} / \\
\mathrm{COD}(\mathrm{g} / \mathrm{g})\end{array}$ & $\begin{array}{l}\text { B: } \mathrm{H}_{2} \mathrm{O}_{2} / \\
\mathrm{Fe}(\mathrm{g} / \mathrm{g})\end{array}$ & $\mathrm{C}: \mathrm{pH}$ & $\begin{array}{l}\text { COD } \\
\text { removal }(\%)\end{array}$ \\
\hline 1 & 11.5 & 1.41 & 4.0 & 78.7 \\
\hline 2 & 3.5 & 1.41 & 4.0 & 70 \\
\hline 3 & 3.5 & 0.35 & 5.0 & 65.3 \\
\hline 4 & 3.5 & 2.47 & 4.0 & 65.8 \\
\hline 5 & 9.5 & 1.41 & 2.0 & 76 \\
\hline 6 & 11.5 & 2.47 & 5.0 & 74.2 \\
\hline 7 & 11.5 & 0.35 & 5.0 & 73.8 \\
\hline 8 & 11.5 & 0.35 & 2.0 & 76.4 \\
\hline 9 & 3.5 & 2.47 & 4.0 & 68 \\
\hline 10 & 3.5 & 0.88 & 3.0 & 72.4 \\
\hline 11 & 1.5 & 0.35 & 4.0 & 62.7 \\
\hline 12 & 9.5 & 3 & 4.0 & 78.2 \\
\hline 13 & 1.5 & 3 & 3.0 & 58.7 \\
\hline 14 & 7.5 & 1.41 & 5.0 & 71.8 \\
\hline 15 & 11.5 & 3 & 2.0 & 77.1 \\
\hline 16 & 9.5 & 2.47 & 3.0 & 82.4 \\
\hline 17 & 3.5 & 1.94 & 3.0 & 75.1 \\
\hline 18 & 3.5 & 3 & 5.0 & 63.3 \\
\hline 19 & 7.5 & 1.41 & 5.0 & 73.6 \\
\hline 20 & 3.5 & 0.35 & 2.0 & 68.4 \\
\hline 21 & 3.5 & 0.88 & 3.0 & 74 \\
\hline 22 & 7.5 & 0.35 & 2.0 & 74.4 \\
\hline 23 & 7.5 & 1.41 & 3.0 & 80.4 \\
\hline 24 & 7.5 & 0.35 & 4.0 & 74.9 \\
\hline 25 & 1.5 & 1.94 & 2.0 & 64.4 \\
\hline 26 & 11.5 & 0.35 & 3.0 & 79.1 \\
\hline 27 & 1.5 & 1.41 & 5.0 & 61.1 \\
\hline 28 & 9.5 & 2.47 & 3.0 & 84.7 \\
\hline 29 & 11.5 & 1.41 & 4.0 & 80 \\
\hline 30 & 5.5 & 3 & 2.0 & 73.1 \\
\hline
\end{tabular}

variables represents COD removal based on the reduced cubic model fitted to the experimental results (Eq. 8).

$$
\begin{aligned}
\text { COD removal }(\%)= & +78.43+7.84 A+1.00 B-6.28 C \\
& +2.28 A B+0.55 A C-5.20 A^{2} \\
& -2.16 B^{2}-3.9 C^{2}-2.60 A^{2} B \\
& +1.80 A B^{2}-1.67 A C^{2}+4.53 C^{3}
\end{aligned}
$$

$A, B$, and $C$ were already introduced in Table 3 .

According to Table 4, the Model $F$-value of 61.94 implies that the model is significant. There is a chance of only $0.01 \%$ that a "Model $F$-Value" as large as this would occur due to noise. The "Lack of Fit $F$-value" of 0.95 implies that the Lack of Fit is not significantly relative to the pure error. The "Adequate Precision" measures the signal to noise ratio. The ratio of 27.824 indicates an adequate signal; thus, this model can be used to navigate the design space.

Optimal treatment conditions

In this study, COD removal was used as an indicator of successful wastewater treatment. In general, the success of the Fenton treatment depends on the generation of $\mathrm{OH}$. Figure 2 shows the response surface of COD reduction due to the interaction between $\mathrm{COD} / \mathrm{H}_{2} \mathrm{O}_{2}$ and $\mathrm{H}_{2} \mathrm{O}_{2} / \mathrm{Fe}$ ratios at $\mathrm{pH}$ 3.0.

Higher concentrations of $\mathrm{H}_{2} \mathrm{O}_{2} / \mathrm{COD}$ in the presence of iron generated more hydroxyl radicals and enhanced process efficiency. However, excessive amounts of hydrogen peroxide and $\mathrm{Fe}$ particles had adverse effects on removal efficiency. The undesirable reactions between hydroxyl/hydroperoxyl radicals and excessive amounts of $\mathrm{H}_{2} \mathrm{O}_{2}$ and $\mathrm{Fe}$ ions may be explained by the following Eqs. $(9,10,11,12)$.

$$
\begin{aligned}
& \mathrm{H}_{2} \mathrm{O}_{2}+\mathrm{OH} \rightarrow \mathrm{HO}_{2}+\mathrm{H}_{2} \mathrm{O} \\
& \mathrm{Fe}^{2+}+\mathrm{OH}^{-} \rightarrow \mathrm{OH}^{-}+\mathrm{Fe}^{3+} \\
& \mathrm{Fe}^{2+}+\mathrm{HO}_{2} \rightarrow \mathrm{HO}_{2}^{-}+\mathrm{Fe}^{3+} \\
& \mathrm{Fe}^{3+}+\mathrm{HO}_{2} \rightarrow \mathrm{O}_{2}+\mathrm{Fe}^{2+}+\mathrm{H}^{+}
\end{aligned}
$$

Although higher concentrations of $\mathrm{Fe}$ ions might have been advantageous in terms of COD reduction by postcoagulation, a high dosage of iron ions scavenged the hydroxyl/hydroperoxyl radicals (Benatti et al. 2006; Kang and Hwang 2000).

As the results show (Fig. 3), pH is also a determinant factor in the Fenton process.

The highest concentration of $\mathrm{Fe}^{2+}$ occurred at $\mathrm{pH}$ values in the range of 2.0-4.0 and beyond which the efficiency decreased. Moreover, hydrogen peroxide is most stable at $\mathrm{pH}$ levels in the range of 3.0-4.0 and its decomposition at higher $\mathrm{pH}$ values formed another reason for the inefficiency of the process (Benatti et al. 2006; Badawy et al. 2006). As seen in Fig. 3, maximum COD removal was obtained at a $\mathrm{pH}$ value of around 3.0 with $\mathrm{COD}$ removal steadily decreasing as $\mathrm{pH}$ increased. These results agree well with those reported in the literature (Kallel et al. 2009; Badawy et al. 2006; Kang and Hwang 2000).

The optimal conditions derived from the experiments conducted are presented in Table 5. These values were employed in the investigation of the reaction kinetics and post-coagulation in the Fenton process. 
Table 4 Analysis of variance for response surface reduced cubic model

\begin{tabular}{|c|c|c|c|c|c|}
\hline Source & Sum of squares & DOF & Mean square & $F$ value & $p$ value $>F$ \\
\hline Model & $1,232.64$ & 12 & 102.72 & 61.94 & $<0.0001$ \\
\hline$A: \mathrm{H}_{2} \mathrm{O}_{2} / \mathrm{COD}$ & 245.64 & 1 & 245.64 & 148.13 & $<0.0001$ \\
\hline$B: \mathrm{H}_{2} \mathrm{O}_{2} / \mathrm{Fe}$ & 4.55 & 1 & 4.55 & 2.74 & 0.1161 \\
\hline$C: \mathrm{pH}$ & 52.92 & 1 & 52.92 & 31.91 & $<0.0001$ \\
\hline$A B$ & 39.97 & 1 & 39.97 & 24.1 & 0.0001 \\
\hline$A C$ & 2.39 & 1 & 2.39 & 1.44 & 0.2464 \\
\hline$A^{2}$ & 102.41 & 1 & 102.41 & 61.75 & $<0.0001$ \\
\hline$B^{2}$ & 22.33 & 1 & 22.33 & 13.47 & 0.0019 \\
\hline$C^{2}$ & 87 & 1 & 87 & 52.46 & $<0.0001$ \\
\hline$A^{2} B$ & 12.89 & 1 & 12.89 & 7.78 & 0.0126 \\
\hline$A B^{2}$ & 8.5 & 1 & 8.5 & 5.13 & 0.0369 \\
\hline$A C^{2}$ & 8.28 & 1 & 8.28 & 4.99 & 0.0392 \\
\hline$C^{3}$ & 24.66 & 1 & 24.66 & 14.87 & 0.0013 \\
\hline Residual & 28.19 & 17 & 1.66 & & \\
\hline Lack of fit & 19.57 & 12 & 1.63 & 0.95 & 0.5699 \\
\hline Pure error & 8.62 & 5 & 1.72 & & \\
\hline Total & $1,260.83$ & 29 & & & \\
\hline
\end{tabular}

$R^{2}=0.9776$

Adjusted $R^{2}=0.9619$

Adequate precision $=27.824$

Fig. 2 Response surface (a) and contour plot (b) for the effects of $\mathrm{H}_{2} \mathrm{O}_{2} / \mathrm{Fe}$ and $\mathrm{H}_{2} \mathrm{O}_{2}$ / COD ratios on COD removal $(\mathrm{pH} 3.0$, reaction time $90 \mathrm{~min})$
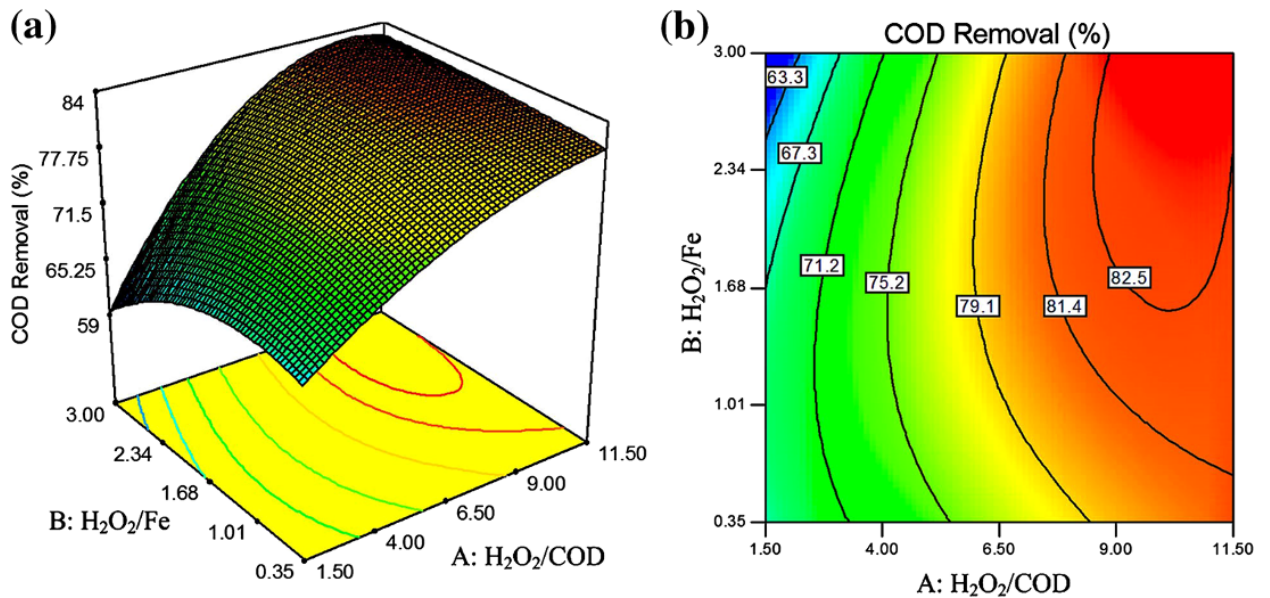

Kinetics studies

Figure 4 shows the variation of COD content versus reaction time after $180 \mathrm{~min}$.

As can be seen, a rapid COD removal was achieved early on so that more than $60 \%$ of COD removal occurred within the first 20 min. While COD reached near its constant value after around 90 min of the reaction time.

The order of reaction was determined by plotting the experimental data functionally, based on the integrated form of the rate expression for a batch reactor. The following expression is for an $n$ th-order reaction carried out in a batch reactor.

$$
\frac{\mathrm{dCOD}}{\mathrm{d} t}=-k \mathrm{COD}^{n}
$$

where $n$ is the reaction order and $k$ is the reaction rate constant. Integrating the above expression for different reaction orders, between the limits from $\mathrm{COD}=\mathrm{COD}_{0}$ to $\mathrm{COD}=\mathrm{COD}$ and from $t=0$ to $t=t$, results in

$\mathrm{COD}-\mathrm{COD}_{0}=-k_{0} t$

$\ln \frac{\mathrm{COD}}{\mathrm{COD}_{0}}=-k_{1} t$

$$
\frac{1}{\mathrm{COD}}-\frac{1}{\mathrm{COD}_{0}}=k_{2} t
$$


Fig. 3 Response surface (a) and contour plot (b) for the effects of $\mathrm{H}_{2} \mathrm{O}_{2} / \mathrm{Fe}$ and $\mathrm{pH}$ on COD removal $\left(\mathrm{H}_{2} \mathrm{O}_{2} / \mathrm{COD}\right.$ 10.03 , reaction time $90 \mathrm{~min}$ )
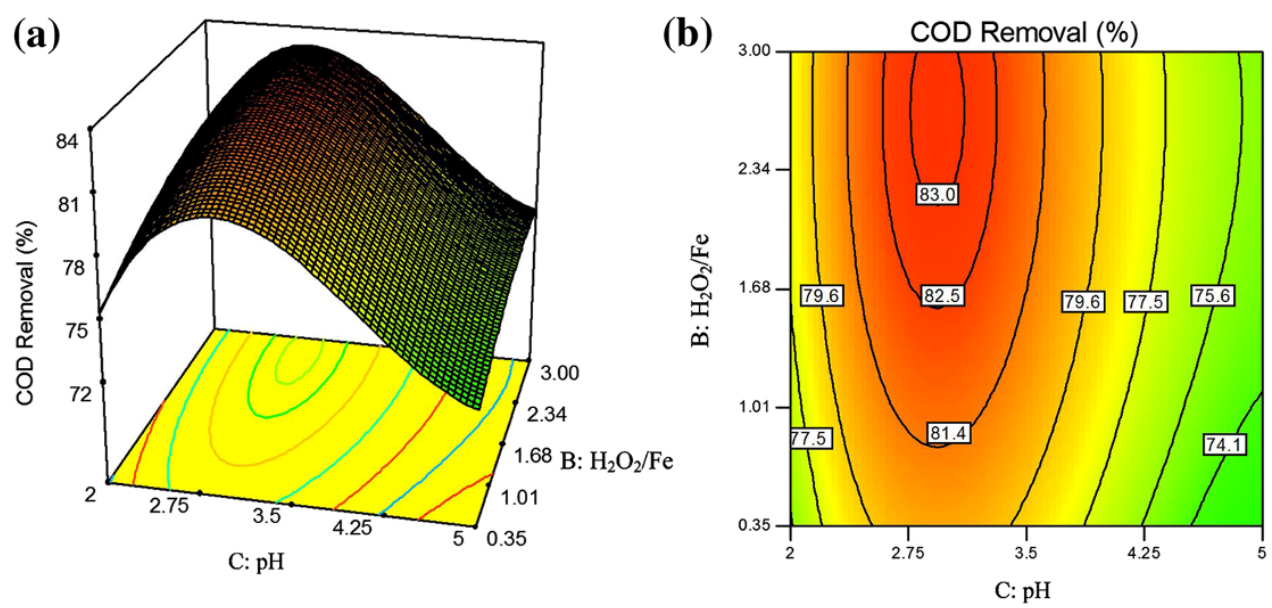

Table 5 Optimal conditions predicted by the software

\begin{tabular}{llllll}
\hline $\begin{array}{l}\text { Predicted COD } \\
\text { removal }(\%)\end{array}$ & $\begin{array}{l}\mathrm{H}_{2} \mathrm{O}_{2} / \mathrm{COD} \\
(\mathrm{g} / \mathrm{g})\end{array}$ & $\begin{array}{l}\mathrm{H}_{2} \mathrm{O}_{2} / \mathrm{Fe} \\
(\mathrm{g} / \mathrm{g})\end{array}$ & $\mathrm{pH}$ & $\begin{array}{l}\mathrm{H}_{2} \mathrm{O}_{2} \\
(\mathrm{~g} / \mathrm{L})\end{array}$ & $\begin{array}{l}\mathrm{Fe} \\
(\mathrm{g} / \mathrm{L})\end{array}$ \\
\hline 83.1 & 10.03 & 2.66 & 3.0 & 4.51 & 1.7 \\
\hline
\end{tabular}

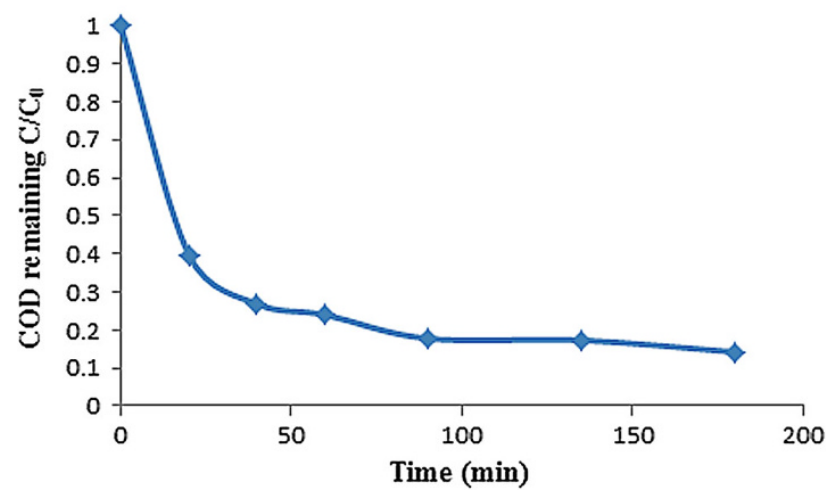

Fig. 4 COD removal under optimal conditions

where COD represents its value at $t=t, \mathrm{COD}_{0}$ is the initial $\mathrm{COD}$, and $k_{0}, k_{1}$, and $k_{2}$ are zero-, first-, and second-order rate constants, respectively (Tchobanoglous et al. 2003).

Figure 5 represents the graphical analysis for determination of reaction order and reaction rate of the process using above equations.

As it can be seen, the linear regression analysis indicates that the second-order reaction model with the slope of $k_{2}=7 \times 10^{-5} \mathrm{~L} \mathrm{mg}^{-1} \mathrm{~min}^{-1}$ could be a better describe for the treatment process than the other reaction orders. Similar observations by other researchers have been reported describing the Fenton process by a second-order reaction model (Su et al. 2011; Szpyrkowicz et al. 2001; Leong and Bashah 2012).
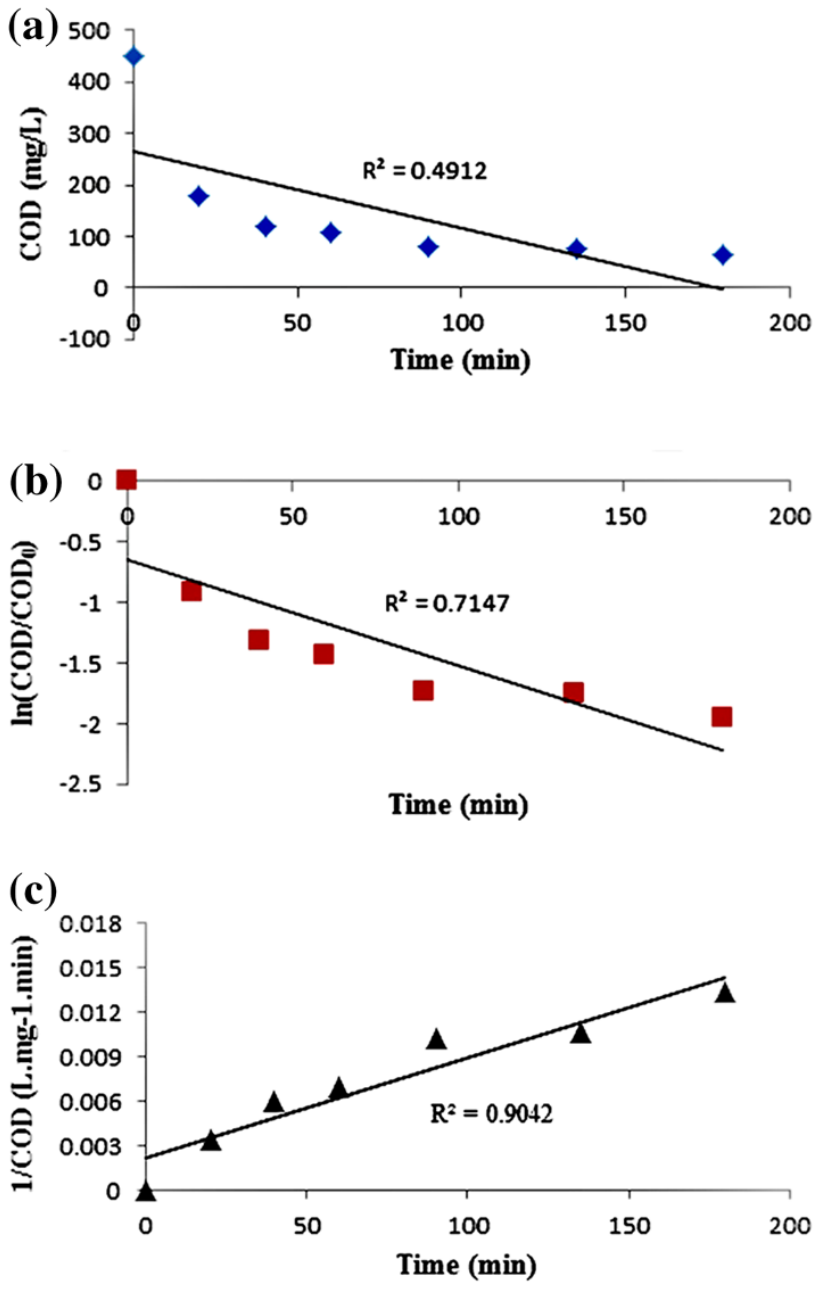

Fig. 5 Graphical analysis for the determination of reaction order and reaction rate constants: (a) zero-order reaction, (b) first-order reaction, and (c) second-order reaction

Post-coagulation process

In addition to the mineralization of organic compounds due to reaction with hydroxyl radicals discussed above, the 


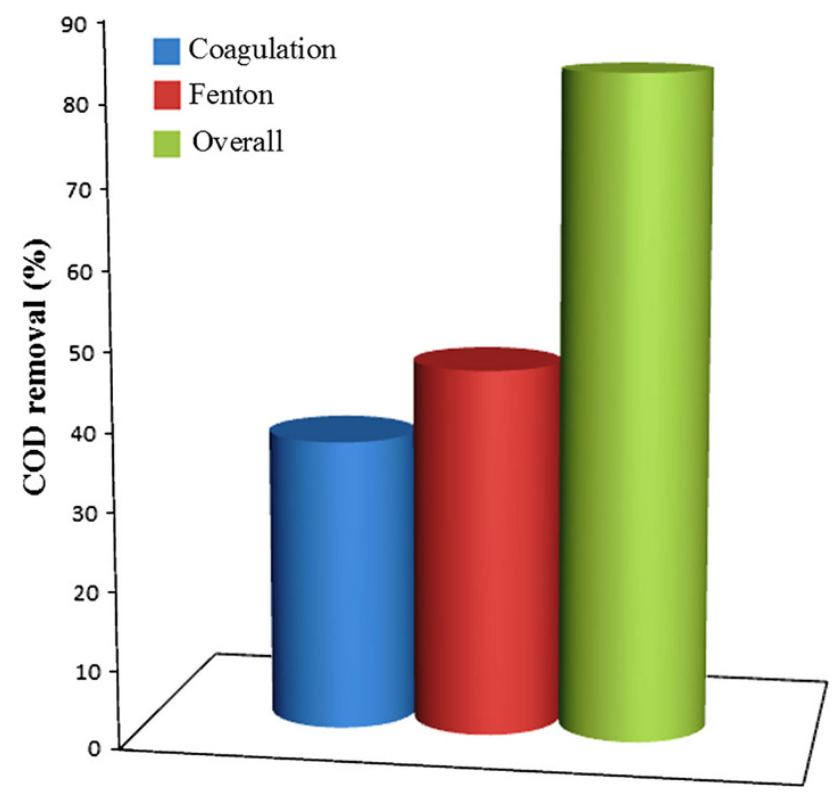

Fig. 6 Contribution of both Fenton oxidation and post-coagulation to the overall treatment efficiency

Fenton treatment also includes a second stage, i.e. removal by coagulation. While in most of literatures the precipitation of iron ions has just been considered as a stage to remove them from the solution and terminate the oxidation, it can be exploited as a post-coagulation process to enhance the overall treatment efficiency. Hydrolyzed metal ions in the solution can act as coagulants by neutralizing charge of colloidal particles (adsorption of metal ions onto the surface particles) and promoting them to agglomerate, or by bridging between two or more particles, which eventually leads to settling of the flocs; nevertheless, the dominant removal mechanism in the post-coagulation process is enmeshment of colloidal particles by sweeping flocs of metal hydroxide (Tchobanoglous et al. 2003; Altaher et al. 2011). This mechanism may occur due to the precipitation of iron hydroxides by modulating $\mathrm{pH}$ to 8.5 to terminate the Fenton reactions. As flocs of metal hydroxide precipitate, the colloidal particles can become entrapped in sweeping flocs and be removed from the wastewater. Efficiency of this process depends on the formation and precipitation of iron hydroxide flocs. The solubility of $\mathrm{Fe}(\mathrm{OH})_{3}$ is a function of $\mathrm{pH}$ and the optimum $\mathrm{pH}$ range for the sweep floc mechanism is between 7.0 and 9.0 (Tchobanoglous et al. 2003; Altaher et al. 2011; Yoon et al. 2002).

In this study, the post-coagulation process was investigated using $1.7 \mathrm{~g} / \mathrm{L}$ iron (optimal concentration for the Fenton process) without introduction of $\mathrm{H}_{2} \mathrm{O}_{2}$ (the other experimental conditions were the same of those used for the Fenton process). According to Fig. 6, about $37 \%$ of the overall COD removal was due to coagulation, accounting for a high potential for removing organics that allows it to be exploited as an auxiliary process to the advanced oxidation stage.

Therefore, considering the Fenton treatment as the combination of advanced oxidation and post-coagulation processes, and optimizing the other determinant factors in the post-coagulation process such as mixing time and velocity, coagulant dosage, temperature, etc., would make the Fenton treatment a promising method for treating recalcitrant wastewaters.

\section{Conclusion}

The results confirmed that the Fenton treatment with scrap iron is an effective method for the pre-treatment of petroleum refinery wastewaters containing high concentrations of recalcitrant compounds. Over $83 \%$ of the COD was removed within $90 \mathrm{~min}$ at $\mathrm{pH} 3.0$ and at mass ratios of 10.03 and 2.66 for $\mathrm{H}_{2} \mathrm{O}_{2} / \mathrm{COD}$ and $\mathrm{H}_{2} \mathrm{O}_{2} / \mathrm{Fe}$, respectively. Compared to iron salts, scrap iron used in the Fenton treatment has a twofold advantage: possibility of multiple use and low costs. The post-coagulation process after Fenton oxidation is an advantageous stage and should be investigated and optimized individually to enhance overall treatment efficiency.

Acknowledgments The authors would like to thank the National Iranian Oil Refining \& Distribution Company for their financial support. Thanks also go to Dr. Ezzatollah Roustazadeh from ELC of IUT for his editing of the first English draft of this manuscript.

Open Access This article is distributed under the terms of the Creative Commons Attribution License which permits any use, distribution, and reproduction in any medium, provided the original author(s) and the source are credited.

\section{References}

Ahmadi M, Vahabzadeh F, Bonakdarpour B, Mofarrah E, Mehranian M (2005) Application of the central composite design and response surface methodology to the advanced treatment of olive oil processing wastewater using Fenton's peroxidation. J Hazard Mater 123(1-3):187-195. doi:10.1016/j.jhazmat.2005.03.042

Altaher H, ElQada E, Omar W (2011) Pretreatment of wastewater streams from petroleum/petrochemical industries using coagulation. Adv Chem Eng Sci 1:245-251. doi:10.4236/aces.2011. 14035

Anotai J, Lu M-C, Chewpreecha P (2006) Kinetics of aniline degradation by Fenton and electro-Fenton processes. Water Res 40(9):1841-1847. http://dx.doi.org/10.1016/j.watres.2006.02.033

Anotai J, Su C-C, Tsai Y-C, Lu M-C (2010) Effect of hydrogen peroxide on aniline oxidation by electro-Fenton and fluidizedbed Fenton processes. J Hazard Mater 183(1-3):888-893. doi:10.1016/j.jhazmat.2010.07.112 
Aranda E, Marco-Urrea E, Caminal G, Arias ME, García-Romera I, Guillén F (2010) Advanced oxidation of benzene, toluene, ethylbenzene and xylene isomers (BTEX) by Trametes versicolor. J Hazard Mater 181(1-3): 181-186. doi:http://dx.doi.org/ 10.1016/j.jhazmat.2010.04.114

Badawy MI, Ghaly MY, Gad-Allah TA (2006) Advanced oxidation processes for the removal of organophosphorus pesticides from wastewater. Desalination 194(1-3):166-175. doi:10.1016/ j.desal.2005.09.027

Barbusiński K, Majewski J (2003) Discoloration of azo dye Acid Red 18 by Fenton reagent in the presence of iron powder. Pol J Environ Stud 12(2):151-155. http://www.pjoes.com/pdf/12.2/ 151-155.pdf

Benatti CT, Tavares CRG, Guedes TA (2006) Optimization of Fenton's oxidation of chemical laboratory wastewaters using the response surface methodology. J Environ Manage 80(1):66-74. doi:10.1016/j.jenvman.2005.08.014

Bianco B, De Michelis I, Vegliò F (2011) Fenton treatment of complex industrial wastewater: optimization of process conditions by surface response method. $\mathrm{J}$ Hazard Mater 186(2-3):1733-1738. doi:10.1016/j.jhazmat.2010.12.054

Chang S-H, Chuang S-H, Li H-C, Liang H-H, Huang L-C (2009) Comparative study on the degradation of I.C. Remazol Brilliant Blue R and I.C. Acid Black 1 by Fenton oxidation and Fe0/air process and toxicity evaluation. J Hazard Mater 166(2-3): 1279-1288. doi:10.1016/j.jhazmat.2008.12.042

Chu L, Wang J, Dong J, Liu H, Sun X (2012) Treatment of coking wastewater by an advanced Fenton oxidation process using iron powder and hydrogen peroxide. Chemosphere 86(4):409-414. doi:10.1016/j.chemosphere.2011.09.007

Coelho A, Castro AV, Dezotti M, Sant'Anna GL Jr (2006) Treatment of petroleum refinery sour water by advanced oxidation processes. J Hazard Mater 137(1):178-184. doi:10.1016/j. jhazmat.2006.01.051

Design Expert software, version 8, user's Guide (2010). Stat-Ease, USA

Diya'uddeen BH, Daud WMAW, Abdul Aziz AR (2011) Treatment technologies for petroleum refinery effluents: a review. Process Saf Environ 89(2):95-105. doi:10.1016/j.psep.2010.11.003

Eaton AD, Clesceri LS, Rice EW, Greenberg AE (2005) Standard methods for the examination of water and wastewater. Centennial edition, 21st edn. American Public Health Association, Washington, DC

Gernjak W, Krutzler T, Glaser A, Malato S, Caceres J, Bauer R, Fernández-Alba AR (2003) Photo-Fenton treatment of water containing natural phenolic pollutants. Chemosphere 50(1): 71-78. http://dx.doi.org/10.1016/S0045-6535(02)00403-4

Hasan DUB, Abdul Aziz AR, Daud WMAW (2012) Oxidative mineralisation of petroleum refinery effluent using Fenton-like process. Chem Eng Res Des 90(2):298-307. doi:10.1016/j.cherd. 2011.06.010

Kallel M, Belaid C, Mechichi T, Ksibi M, Elleuch B (2009) Removal of organic load and phenolic compounds from olive mill wastewater by Fenton oxidation with zero-valent iron. Chem Eng J 150(2-3):391-395. doi:10.1016/j.cej.2009.01.017

Kang YW, Hwang K-Y (2000) Effects of reaction conditions on the oxidation efficiency in the Fenton process. Water Res 34(10): 2786-2790. doi:10.1016/s0043-1354(99)00388-7

Kavitha V, Palanivelu K (2004) The role of ferrous ion in Fenton and photo-Fenton processes for the degradation of phenol. Chemosphere 55(9):1235-1243. doi:10.1016/j.chemosphere.2003.12. 022

Leong SK, Bashah NAA (2012) Kinetic study on COD removal of palm oil refinery effluent by UV-Fenton. APCBEE Procedia 3:6-10. doi:10.1016/j.apcbee.2012.06.037

Mu Y, Yu H-Q, Zheng J-C, Zhang S-J, Sheng G-P (2004) Reductive degradation of nitrobenzene in aqueous solution by zero-valent iron. Chemosphere 54(7):789-794. doi:10.1016/j.chemosphere. 2003.10.023

Ramirez JH, Duarte FM, Martins FG, Costa CA, Madeira LM (2009) Modelling of the synthetic dye Orange II degradation using Fenton's reagent: From batch to continuous reactor operation. Chem Eng J 148 (2-3): 394-404. http://dx.doi.org/10.1016/j.cej. 2008.09.012

Saien J, Nejati H (2007) Enhanced photocatalytic degradation of pollutants in petroleum refinery wastewater under mild conditions. J Hazard Mater 148(1-2):491-495. doi:10.1016/j.jhazmat. 2007.03.001

Stepnowski P, Siedlecka EM, Behrend P, Jastorff B (2002) Enhanced photo-degradation of contaminants in petroleum refinery wastewater. Water Res 36(9):2167-2172. doi:10.1016/s0043-1354(01) 00450-x

Su C-C, Pukdee-Asa M, Ratanatamskul C, Lu M-C (2011) Effect of operating parameters on decolorization and $\mathrm{COD}$ removal of three reactive dyes by Fenton's reagent using fluidized-bed reactor. Desalination 278(1-3):211-218. doi:10.1016/j.desal. 2011.05.022

Sun J-H, Sun S-P, Fan M-H, Guo H-Q, Qiao L-P, Sun R-X (2007) A kinetic study on the degradation of p-nitroaniline by Fenton oxidation process. J Hazard Mater 148(1-2): 172-177. http://dx. doi.org/10.1016/j.jhazmat.2007.02.022

Szpyrkowicz L, Juzzolino C, Kaul SN (2001) A Comparative study on oxidation of disperse dyes by electrochemical process, ozone, hypochlorite and fenton reagent. Water Res 35(9):2129-2136. doi:10.1016/s0043-1354(00)00487-5

Tchobanoglous G, Burton F, Stensel HD (2003) Metcalf \& Eddy, wastewater engineering, treatment, disposal \& reuse, 4th edn. McGraw-Hill, New York

Tiburtius ERL, Peralta-Zamora P, Emmel A (2005) Treatment of gasoline-contaminated waters by advanced oxidation processes. J Hazard Mater 126(1-3):86-90. doi:10.1016/j.jhazmat.2005.06. 003

Yoon J, Kim Y, Huh J, Lee Y, Lee D (2002) Roles of oxidation and coagulation in Fenton process for the removal of organics in landfill leachate. J Ind Eng Chem 8(5):410-418. http://www. cheric.org/PDF/JIEC/IE08/IE08-5-0410.pdf 